\title{
Anatomia e histoquímica dos órgãos vegetativos de Polygonum hydropiperoides Michx., Polygonaceae
}

\author{
Daniela E. Silva Lopes, ${ }^{1}$ Virgínia Del Carmen Oliveira, ${ }^{*, 2}$ João F. Macedo, ${ }^{3}$ \\ Alaíde Braga de Oliveira, ${ }^{1}$ Rose Lisieux R. Paiva Jácome ${ }^{1}$ \\ ${ }^{1}$ Departamento de Produtos Farmacêuticos, Universidade Federal de Minas Gerais, Av. Antônio Carlos 6227 , \\ Pampulha, 31270-010 Belo Horizonte-MG, Brasil \\ ${ }^{2}$ Fundação Ezequiel Dias, R. Conde Pereira Carneiro 80, 30510-010 Belo Horizonte-MG, Brasil \\ 3Empresa Agropecuária de Minas Gerais, Av. José Cândido da Silveira 1647, Cidade Nova, \\ 31170-000 Belo Horizonte-MG, Brasil
}

\begin{abstract}
RESUMO: Polygonum hydropiperoides Michaux é uma espécie conhecida popularmente como "erva-de-bicho", amplamente utilizada na medicina tradicional como anti-hemorroidal, antiinflamatória e antidiarréica. O presente trabalho tem como objetivo a caracterização anatômica e histoquímica da folha, caule e raiz, que constituem a droga vegetal, visando estabelecer parâmetros para o controle de qualidade. O material vegetal foi fixado e submetido às técnicas usuais de microscopia de luz e aos testes histoquímicos. A folha é anfiestomática, dorsiventral e com estômatos paracíticos e anisocíticos. É comum a presença de estruturas secretoras como: tricomas glandulares capitados e glândulas epidérmicas e subepidérmicas em ambas as faces da lâmina foliar e também no caule. $\mathrm{O}$ material secretado pelas glândulas apresenta composição heterogênea de lipídios e flavonóides, segundo análises histoquímicas. Cristais de oxalato de cálcio e grãos de amido são freqüentes em células parenquimáticas da folha e do caule. Compostos fenólicos estão presentes na folha (parênquima paliçádico), no caule (parênquima cortical e floema) e na raiz (parênquima cortical).
\end{abstract}

Unitermos: Polygonum hydropiperoides, Polygonaceae, estruturas secretoras, testes histoquímicos, controle de qualidade.

\begin{abstract}
Anatomical and histochemical characters of Polygonum hydropiperoides Michaux, Polygonaceae". P. hydropiperoides is popularly known as "erva-de-bicho", and it is used in traditional medicine as anti-hemorroidal, anti-inflammatory and antidiarrhoeic. The present work has as objective the anatomical and histochemical characterization of leaf, stem and root that are used as drug in order to offer elements for quality control. The botanical material was prepared for the usual optical and histochemical microtechniques. The leaf is amphistomatic, dorsiventral and paracytic and anisocytic stomata. It is common to find the presence of secretory structures as: capitate glandular trichomes and secretory glands on both epidermis, that are also present in stem. The secretion material is heterogeneous composition of lipids and flavonoids. Druses of calcium oxalate and starch are common in parenchyma cells of leaf and stem. Phenolic compounds are present in leaf (palisade parenchyma), in stem (cortical parenchyma and phloem) and root (cortical parenchyma).
\end{abstract}

Keywords: Polygonum hydropiperoides, Polygonaceae, secretory structures, histochemical test, quality control.

\section{INTRODUÇÃO}

Polygonum hydropiperoides Michaux é um representante da família Polygonaceae que possui cerca de quarenta gêneros, com mais de oitocentas espécies distribuídas nas regiões tropicais, temperadas e subtropicais (Barroso, 1978). Espécies de Polygonum são consideradas plantas invasoras, ocorrendo desde áreas agrícolas especialmente úmidas ou sob regime de irrigação, até praças e jardins dos centros urbanos (Embrapa, 2005; Macedo, 1993) Algumas são medicinais e usadas em cosméticos como Polygonum bistorta, Polygonum punctatum, Polygonum persicaria e Polygonum stypticum (Leitão et al., 2009; Mariath et al., 2009; Agra et al., 2008; Biavatti et al., 2007). Na Cadeia do Espinhaço, extensão dos estados de Minas Gerais e Bahia, as espécies: $P$. meisnerianum, $P$. punctatum, $P$. hydropiperoides, $P$. hispidum, $P$. acuminatum, $P$. ferrugineum são encontradas 
nas margens de rios, lagoas e locais inundáveis (Melo, 2000).

Vários autores descreveram as características anatômicas das folhas do gênero Polygonum tais como: ocorrência de estômatos do tipo anisocítico, diacítico ou paracítico; tricomas unicelulares ou pluricelulares; tricomas glandulares variando o número de células que formam a porção distal de duas a vinte células; glândulas amplamente distribuídas; parênquima paliçádico variando de uma a quatro camadas e presença de drusas e grãos de amido (Gattuso, 2001; Silva-Brambilla \& Moscheta, 2001; Lersten \& Curtis, 1992; Mitchell, 1971; Metcalfe \& Chalk, 1950).

P. hydropiperoides, conhecida popularmente como "erva-de-bicho", é a espécie de maior dispersão no Estado de Minas Gerais (Macedo, 1993). É uma planta anual, herbácea, de hábito ereto a semiprostrado, com cerca de 40 a $100 \mathrm{~cm}$ de altura, com ramos glabros ou escassamente pilosos e geralmente avermelhados; folhas inteiras, subsésseis, lanceoladas, alternas; inflorescências terminais, de espigas geminadas, delicadas, com poucas flores de coloração branca ou rosada (Melo, 2000; Martins et al., 1995; Macedo, 1993; Simões et al., 1986; Correa, 1969).

$\mathrm{Na}$ medicina popular é utilizada como antiiflamatória, anti-hemorroidal e antidiarréica (Gupta, 1995; Correa, 1969). Investigações farmacológicas de $P$. hydropiperoides mostraram atividade antiedematogênica muito acentuada e ausência de toxicidade aguda e sub aguda na dose de $250 \mathrm{mg} \mathrm{kg}^{-1}$ (Bianchi et al., 1993; Oliveira et al., 1991).

O presente trabalho tem como objetivo o estudo anatômico e histoquímico dos órgãos vegetativos da espécie $P$. hydropiperoides visando estabelecer parâmetros para o controle de qualidade da droga vegetal.

\section{MATERIAL E MÉTODOS}

Amostras de caule, folha e raiz foram coletadas em Novembro de 2001 em Nova Serrana, Minas Gerais, em local alagado e ensolarado. A exsicata foi incorporada ao acervo do Herbário PAMG, da Empresa Agropecuária de Minas Gerais (EPAMIG) sob o número 55034.

Para a análise anatômica, as amostras coletadas de $P$. hydropiperoides foram fixadas em FAA 70 (Johansen, 1940) e conservadas em álcool $70 \%$. As secções transversais foram realizadas à mão livre e obtidas do ápice da raiz, do segundo entrenó do caule e da região mediana da folha do terceiro nó. Foram coradas segundo técnica descrita por Bukatsch (1972), com safranina e azul de astra (2:8, $\mathrm{v} / \mathrm{v})$. A epiderme foi analisada através da dissociação de fragmentos de lâmina foliar utilizando-se mistura de Jeffrey (Johansen, 1940), diafanizada com hipoclorito de sódio a 1\% (Bersier \& Bocquet, 1960), corada com safranina 1\% (Johansen, 1940) e montada em gelatina glicerinada.

O pó obtido da planta toda de $P$. hydropiperoides, após secagem e moagem da amostra coletada foi diafanizado com hipoclorito de sódio a 1\% (Bersier \& Bocquet, 1960), centrifugado, lavado e as lâminas foram montadas em gelatina glicerinada.

Os testes histoquímicos foram efetuados utilizando material fresco. Os cortes obtidos foram submetidos aos seguintes reagentes: Sudan IV (Foster, 1949) para detecção de lipídios, cutina e suberina; DMACA ( $p$-dimetilaminocinamaldeído) para flavonóides (Feucht \& Schmid, 1983), reagente de Nadi (David \& Carde, 1964) para avaliação de terpenos e lugol para amido (Lageron, 1949). A presença de compostos fenólicos foi avaliada com solução de sulfato ferroso a $2 \%$ em formalina $4 \%$ (Johansen, 1940). Para a realização de testes controle, derivados fenólicos e flavônicos foram extraídos com reagente de Stockwell (Johansen 1940) por 24 h e lipídios com clorofórmio:metanol (2:1) v/v (Moore et al., 1991).

As fotomicrografias foram obtidas com microscópio Olympus CBA acoplado a uma câmara fotográfica Olympus PM-6.

\section{RESULTADOS}

As células epidérmicas fundamentais, em vista frontal, são poliédricas, de paredes anticlinais retas ou levemente sinuosas na face adaxial (Figura 2) e apresentam maior sinuosidade na face abaxial (Figura 1). Sobre as nervuras, as células apresentam-se retangulares com as paredes retas (Figura 1). Os estômatos são em sua maioria do tipo paracítico, sendo uma das células subsidiárias maior (Figura 3), podendo ocorrer alguns estômatos do tipo anisocítico (Figura 5).

Tricomas tectores multisseriados, de paredes espessadas ocorrem na nervura principal e no bordo foliar (Figura 10).

Em vista frontal observam-se glândulas compostas por quatro células envolvendo um pequeno poro na região central, e rodeadas por pequenas células, seguidas pelas células epidérmicas fundamentais (Figura 5). Esse poro comunica-se com a cavidade subepidérmica da glândula (Figura 6). Também ocorrem tricomas glandulares distribuídos em ambas as faces, localizados em pequenas depressões da epiderme, formados por quatro células na sua porção distal e por uma célula peduncular curta (Figuras 3 e 4 ).

Em secção transversal as glândulas mostram-se formadas por duas células epiteliais de formato côncavo justapostas, as quais estão envolvidas por várias células menores que delimitam-se com o mesofilo (Figuras 6 e 8). Esta estrutura é composta na sua porção central por uma grande cavidade que se encontra preenchida por substâncias que através de testes histoquímicos revelaram composição de lipídios e flavonóides, respectivamente (Figuras 19 e 20). A presença de flavonóides é evidenciada por uma coloração azul anil (Figura 20).

A folha é anfiestomática com a epiderme 
uniestratificada em ambas as faces (Figuras 7 e 17). A epiderme da face abaxial difere da face adaxial pelo tamanho das células, sendo estas últimas de maior tamanho (Figuras 7 e 17). Suas paredes periclinais externas encontram-se revestidas por uma cutícula fina e lisa de natureza lipídica, mais evidente junto a nervura principal (Figura 18). O parênquima paliçádico é constituído de uma camada de células (Figuras 7 e 8) e através de testes histoquímicos foi evidenciada a presença de compostos fenólicos (Figuras 16 e 17). O parênquima esponjoso apresenta-se compacto formado por duas a três camadas de células de forma elíptica (Figura 7); os feixes vasculares de menor calibre são colaterais e estão envolvidos pela endoderme (Figuras 7 e 8). Glândulas epidérmicas e subepidérmicas são observadas tanto na face adaxial como abaxial e exibem formato esférico, interrompendo eventualmente o parênquima paliçádico e esponjoso (Figuras 6, 8, 19 e 20). Idioblastos globosos contendo drusas são observados com maior freqüência no parênquima esponjoso, próximo ao parênquima paliçádico (Figura 8).

A nervura central em seç̧ão transversal, apresenta contorno biconvexo, mais proeminente na face abaxial (Figura 9). A epiderme é uniestratificada, as células possuem contorno arredondado (Figura 9), com tricomas tectores multisseriados (Figura 10). O colênquima angular ocorrendo junto a ambas as faces é constituído de uma a quatro camadas de células na face adaxial e de uma a duas camadas na face abaxial (Figura 9). O parênquima paliçádico é interrompido pelo colênquima e o parênquima cortical apresenta amplos espaços intercelulares, principalmente junto à face abaxial (Figura 9). O sistema vascular da nervura central, na região mediana da folha, é constituído por quatro feixes colaterais dispostos em círculo e as fibras ocorrem externamente ao floema (Figura 9). Grãos de amido e drusas são comuns no parênquima cortical (Figura 11).

O caule jovem em início de desenvolvimento secundário, em secção transversal, mostra epiderme unisseriada formada de células aproximadamente retangulares, com a parede periclinal externa, mais espessa, colênquima angular subepidérmico com duas a três camadas de células, parênquima cortical com células arredondadas e espaços intercelulares, idioblastos contendo drusas, feixes vasculares colaterais, câmbio interfascicular e fibras pericíclicas formando um anel concêntrico (Figura 12). Compostos fenólicos foram encontrados na região cortical e no floema (Figura 14). A secreção das glândulas é heterogênea composta de lipídios e flavonóides, a qual foi observada pela cor alaranjada do Sudam IV e pela cor azul anil do DMACA, respectivamente. Grãos de amido (Figura 12) e drusas são freqüentes no parênquima medular e na região central da medula ocorre uma lacuna (Figura 14).

O caule em estrutura secundária, em secção transversal, possui epiderme unisseriada, formada de células aproximadamente retangulares, com a parede periclinal externa mais espessa e com uma cutícula evidente, colênquima angular subepidérmico com duas a três camadas de células, parênquima cortical com três a quatro camadas de células comprimidas, periciclo esclerificado formando um anel concêntrico e câmbio vascular evidente. O sistema vascular possui floema secundário pouco desenvolvido e o xilema secundário é formado por poucas camadas de elementos de vasos. A região medular é composta por células parenquimáticas arredondadas de paredes finas (Figura 13).

A raiz em estrutura secundária, em secção transversal, é constituída de periderme de quatro camadas de células de composição lipídica, córtex parenquimático pouco desenvolvido, fibras do floema isoladas e/ ou agrupadas, elementos de vaso e fibras de paredes secundárias lignificadas que se dispõem em filas radiais (Figura 15).

O pó de $P$. hydropiperoides apresentou coloração marrom pardacento (Figura 21), com estruturas que se identificam como sendo fragmentos de folha devido à presença de estômatos e às células epidérmicas da folha em vista frontal (Figura 24). Estruturas como drusas e grãos de amido em fragmentos de medula são características indicadoras de caule (Figuras 22 e 23). 

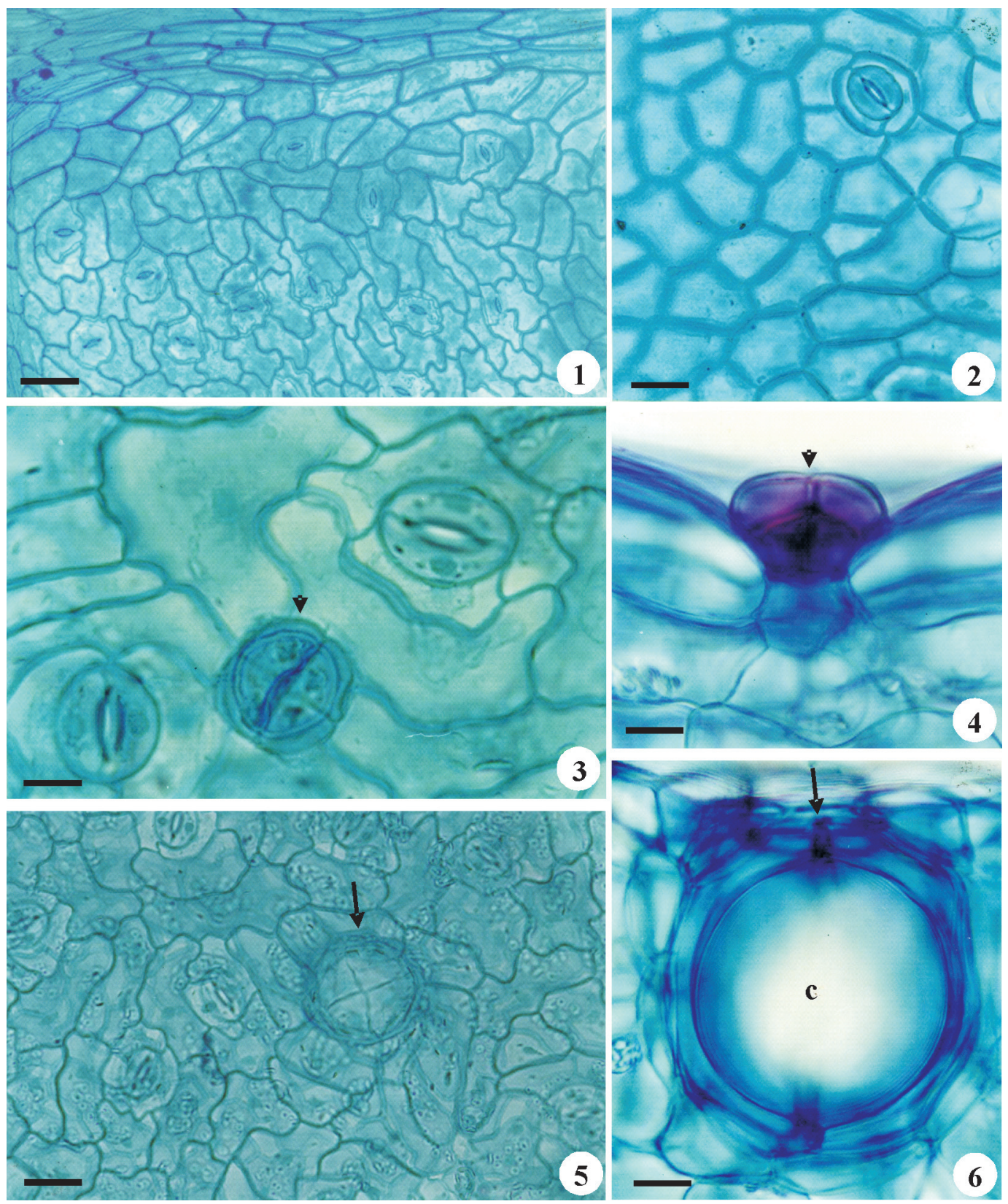

Figuras 1-6. Lâmina foliar de $P$. hydropiperoides Michaux. 1. Epiderme da face abaxial, em vista frontal. 2. Epiderme da face adaxial, em vista frontal. 3. Tricoma glandular capitado (ponta de seta) e estômatos paracíticos. 4. Epiderme com tricoma glandular capitado, em secção transversal (ponta de seta). 5. Glândula secretora (seta) e estômato anisocítico. 6. Glândula secretora, em secção transversal (seta). (c, cavidade). Barra $=50 \mu \mathrm{m}(1,5), 25 \mu \mathrm{m}(2), 10 \mu \mathrm{m}(3,4,6)$. 

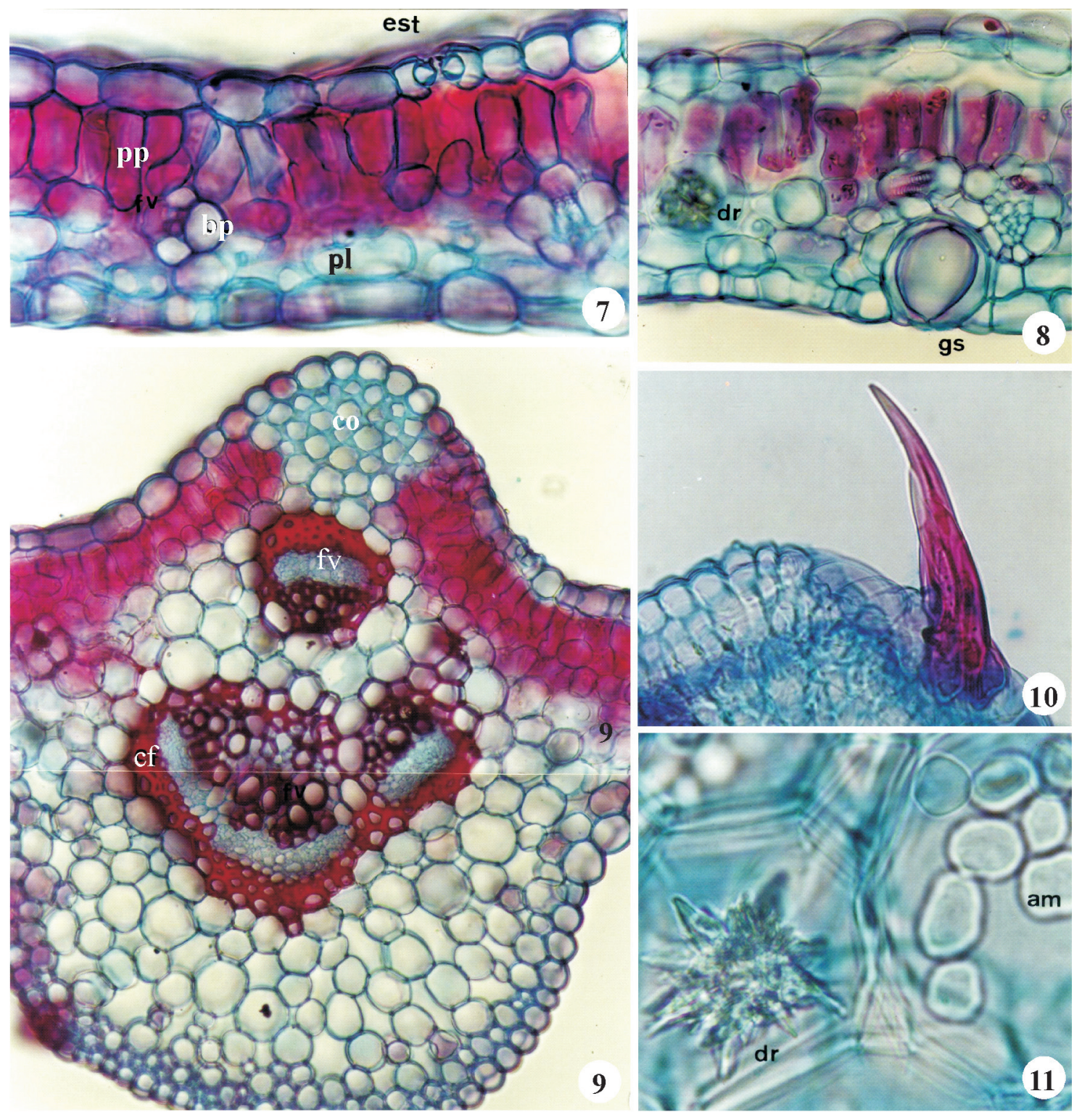

Figuras 7-11. Secções transversais da lâmina foliar de $P$. hydropiperoides Michaux. 7. Epiderme, mesofilo dorsiventral com feixe vascular lateral. 8. Epiderme, mesofilo dorsiventral, feixe vascular lateral, glândula secretora e idioblasto com drusa. 9-11. Nervura central da folha. 9. Sistema vascular em arco. 10. Tricoma tector multisseriado. 11. Drusas e grãos de amido. (am, amido; bp, bainha parenquimática; cf, calota de fibras; co, colênquima angular; dr, drusas; est, estômato; fv, feixe vascular; gs, glândula secretora; pl, parênquima lacunoso; pp, parênquima paliçádico). Barra $=50 \mu \mathrm{m}(9), 25 \mu \mathrm{m}(7,8,10), 10 \mu \mathrm{m}(11)$. 

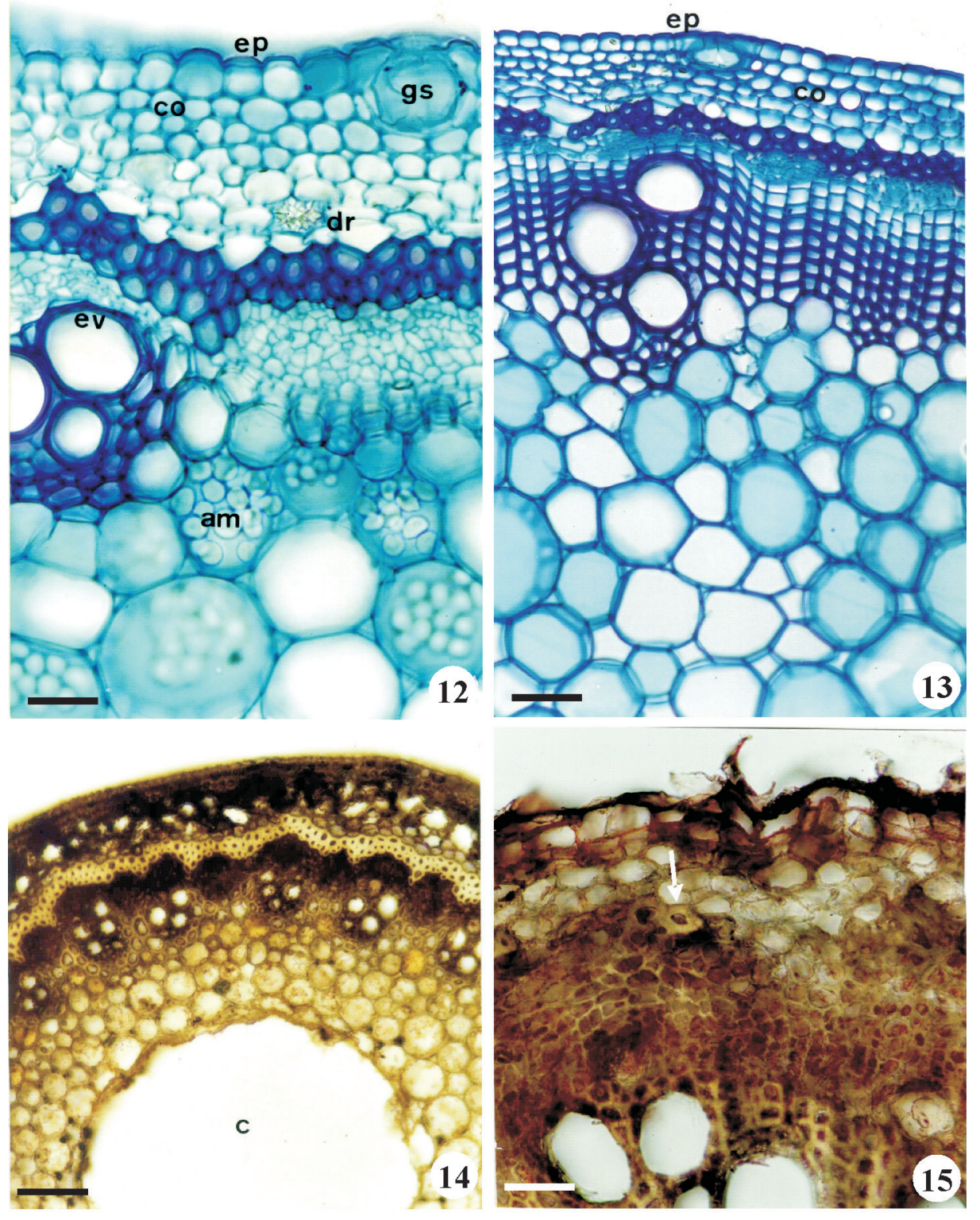

Figuras 12-15. Secções transversais de caule e raiz de $P$. hydropiperoides Michaux. 12. Caule em início de crescimento secundário. 13. Caule em crescimento secundário. 14. Caule, aspecto geral. 15. Raiz em crescimento secundário. (am, amido; la, lacuna; co, colênquima; dr, drusas; ev, elementos de vasos; ep, epiderme unisseriada; gs, glândula secretora; seta, fibras do floema). Barra $=25$ $\mu \mathrm{m}(12), 50 \mu \mathrm{m}(13,15), 100 \mu \mathrm{m}(14)$. 

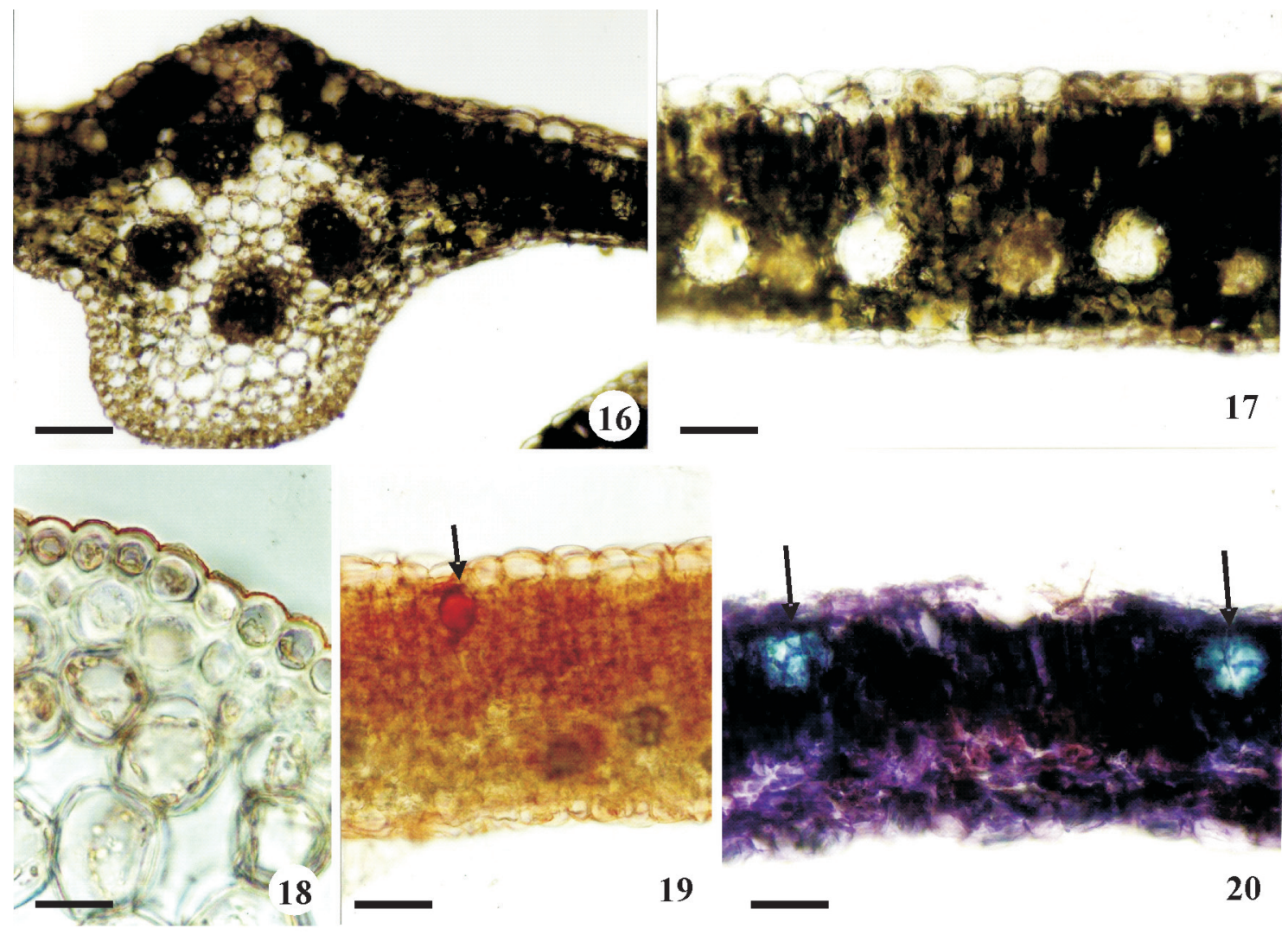

Figuras 16-20. Testes histoquímicos em folha de P. hydropiperoides Michaux. 16. Nervura central com compostos fenólicos. 17. Mesofilo com compostos fenólicos. 18. Cutícula lipídica. 19. Glândula secretora com lipídios (seta). 20. Glândula secretora com flavonóides (seta). Barra $=100 \mu \mathrm{m}(16,19), 50 \mu \mathrm{m}(17,20), 25 \mu \mathrm{m}(18)$.

\section{DISCUSSÃO}

Para a família Polygonaceae, Meltcalfe \& Chalk (1950) descreveram a predominância de estômatos anomocíticos, observados neste trabalho. Porém, outros tipos de estômatos são descritos para a família como anomocíticos, anisocíticos, diacíticos ou paracíticos (Cronquist, 1981). Em P. persicaria, Scavone \& Graeiro (1970) relatam a ocorrência de estômatos paracíticos e em P. hydropiperoides, Mitchell (1971) e Silva-Brambilla \& Moscheta (2001) observaram predominância de estômatos paracíticos em sete espécies de Polygonum. A variabilidade estomática não permite a utilização dessa estrutura como de valor taxonômico para o gênero (Lersten \& Curtis, 1992).

Mitchell (1971) observou células epidérmicas fortemente cutinizadas e Scavone \& Graeiro (1970) inclusões de mucilagens, em espécies de Polygonum, características não observadas neste estudo.

Na lâmina foliar de espécies de Polygonum foi evidenciada a presença de diversos tipos de tricomas unisseriados ou multisseriados (Yano, 1999; Mitchell, 1971; Scavone \& Graeiro, 1970). Lersten \& Curtis
(1992) comentam que alguns tricomas pluricelulares são na verdade, aglomerados de pêlos que formam feixes, semelhantes aos observados neste estudo. Descrevem também que é comum a ocorrência de tricomas glandulares variando o número de células que formam a porção glandular entre duas a vinte sendo sua distribuição em ambas faces da epiderme ou apenas na face abaxial. Tricomas glandulares capitados esferoidais descritos por Lersten \& Curtis (1992) para P. hydropiperoides foram evidenciados neste trabalho.

Silva-Brambilla \& Moscheta (2001) descrevem a presença de idioblastos epidérmicos na face adaxial em $P$. hydropiperoides, entretanto os testes histoquímicos realizados neste estudo mostraram que são glândulas epidérmicas e subepidérmicas que possuem composição heterogênea de lipídios e flavonóides. A existência de compostos flavônicos, também, foi comprovada nos extratos etanólicos e hidroetanólicos da matéria-prima vegetal, através de análise de cromatografia de camada delgada (Jácome et al., 2004).

As glândulas registradas na espécie em estudo já foram relatadas por autores, em espécies de Polygonum, com diversas denominações e tipos de secreção como: cavidades 

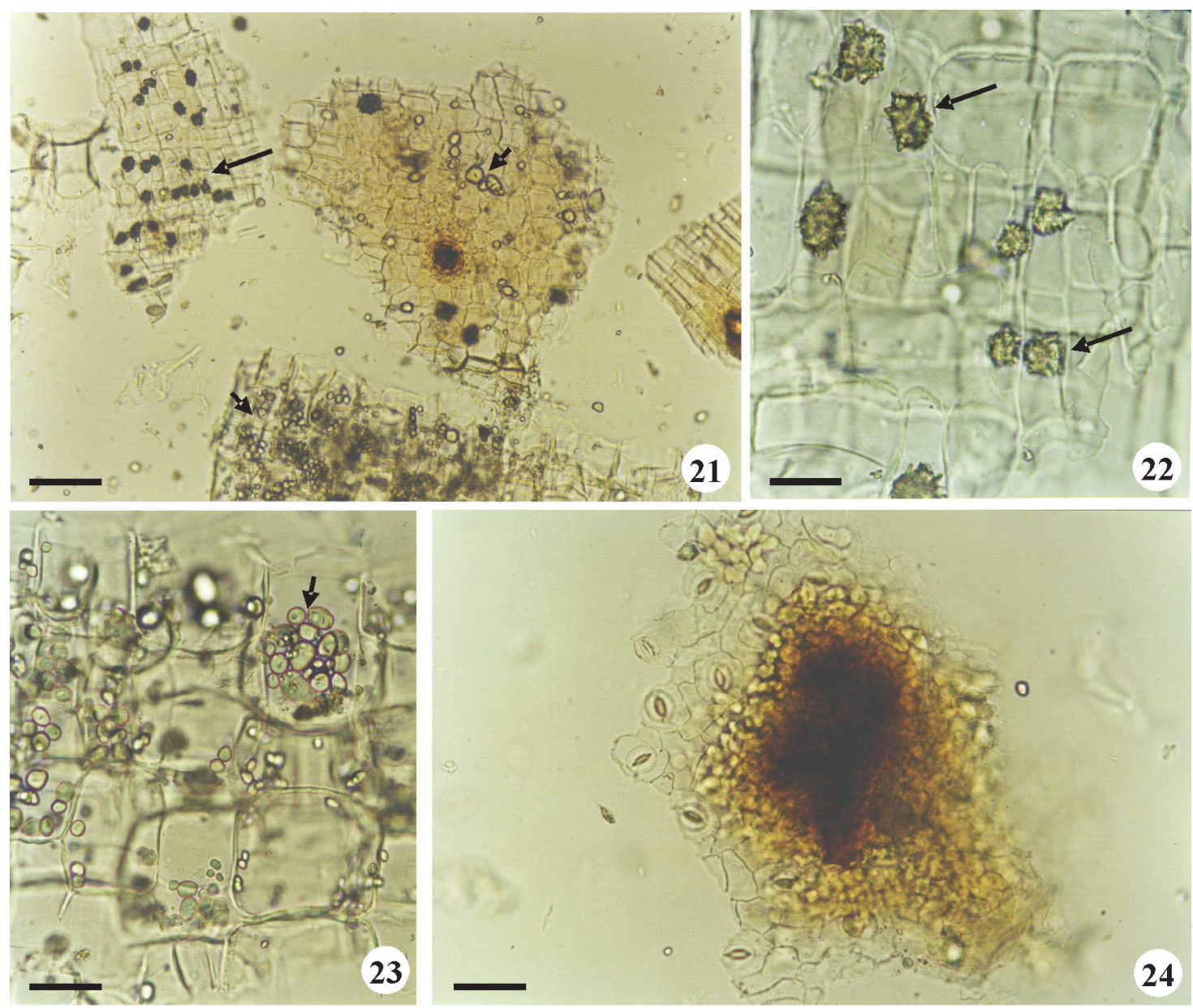

Figuras 21-24. Pó de P. hydropiperoides Michaux. 21. Aspecto geral do pó com drusas (seta) e amido (ponta de seta). 22. Drusas (seta) em células parenquimáticas. 23. Grãos de amido (ponta de seta) em células parenquimáticas. 24. Fragmento de folha. Barra $=$ $100 \mu \mathrm{m}(21,24), 50 \mu \mathrm{m}(23), 25 \mu \mathrm{m}(22)$.

secretoras epidérmicas que contêm óleo-resinas (Gattuso, 2001; Lersten \& Curtis, 1992;); glândulas complexas localizadas em um círculo de células epidérmicas menores (Gattuso, 2001); células armazenadoras de água (Scavone \& Graeiro, 1970; Metcalfe \& Chalk, 1950) e câmaras valváticas excretoras de substâncias irritantes (Mitchell, 1971). Porém, este último autor não observou a presença dessas câmaras em $P$. hydropiperoides. A presença ou ausência da glândula é uma característica de grande valor diagnóstico na delimitação das secções de Polygonum (Gattuso, 2001).

Colênquima angular e lacuna na região central da medula presentes na espécie em estudo também foram registrados em P. persicaria (Yano 1999; Scavone \& Graeiro, 1970). Por outro lado, o periciclo ocorre amplamente no gênero, principalmente em espécies de crescimento rápido (Metcalfe \& Chalk, 1950).

A presença de compostos fenólicos detectados na região cortical caulinar e no mesofilo foliar foi confirmada pelas análises fitoquímicas realizadas nos extratos etanólicos e hidroetanólicos de P. hydropiperoides (Jácome et al., 2004).

As características anatômicas da raiz de $P$. hydropiperoides, como periderme com várias camadas e fibras do floema isoladas e/ou agrupadas, são semelhantes às observadas em $P$. persicaria (Scavone \& Graeiro, 1970).

\section{CONCLUSÕES}

Os estudos anatômicos de $P$. hydropiperoides, espécie de maior ocorrência em Minas Gerais, possibilitaram determinar aspectos importantes como folha anfiestomática, dorsiventral com estômatos paracíticos e anisocíticos, tricomas glandulares capitados na folha e glândulas epidérmicas e subepidérmicas, tanto na folha como no caule. Essas glândulas produzem secreções heterogêneas de lipídios e flavonóides. Os dados obtidos fornecem subsídios para o controle de qualidade da matéria-prima utilizada na produção de fitoterápicos. 


\section{AGRADECIMENTOS}

Ao Laboratório Osório de Moraes e a Fundação de Amparo a Pesquisa de Minas Gerais (FAPEMIG) pela concessão de bolsa de Mestrado a um dos autores (D.E.S.L.)

\section{REFERÊNCIAS}

Agra MF, Silva KN, Basílio IJLD, França PF, Barbosa-Filho JM 2008. Survey of medicinal plants used in the region Northeast of Brazil. Rev Bras Farmacogn 18: 472-508.

Barroso GM1978. Sistemáticadas Magnoliophyta(Angiospermae) In Sistemática de angiospermas do Brasil. São Paulo: Editora da Universidade de São Paulo.

Bersier JD, Bocquet G 1960. Les methods d'éclaircissement em vascularisation et em morphogénie végétales comparées. Arch Sci 13: 555-566.

Bianchi NR, Silva MO, Spiassi L, Machado CA, Bergonci JI 1993. Ensaio de toxicidade excessiva e "screening" fitoquímico de plantas usadas popularmente no tratamento de afecções gastro-intestinais. Rev Bras Farm 74: 50-51.

Biavatti M, Marensi V, Leite SN, Reis A 2007. Ethnopharmacognostic survey on botanical compendia for potential cosmeceutic species from Atlantic Forest. Rev Bras Farmacogn 17: 640-653.

Bukatsch F 1972. Bemerkungen zur Doppelfärbun AstrablauSafranin. Mikrokosmos 61: 255.

Correa MP 1969. Dicionário das plantas úteis do Brasil e das exóticas cultivadas. Rio de Janeiro: Ministério da Agricultura .

Cronquist A 1981. An integrated system of classification of flowering plants. New York: Columbia University Press.

David R, Carde JP 1964. Coloration différentielle des inclusions lipidiques et terpéniques des pseudophylles du Pin maritime au moyen du réactif nadi. $C R$ Acad Sc Paris 258: $1338-1340$.

Embrapa 2005. Plantas daninhas em arroz irrigado. http:// sistemasdeprodução.cnptia.embrapa.br/FontesHTML/ Arroz/ArrozIrrigadoBrasil. Acesso em novembro de 2007.

FeuchtW, Schmid PPS 1983. Selektiver histochemischer nachweis von flavanen (catechinen) mit $p$-dimethylaminozimtaldehyd in sprossen einiger obstgeholzi. Gartenbauwissenschaft 48: 119-124.

Foster AS 1949. Practical plant anatomy. 2 ed. Princeton: D. Van Nostrand Company Inc.

Gattuso SJ 2001. Structure and ultrastructure of the secretory glands in the genus, Polygonum (L.), section Persicaria (Polygonaceae). Biocell 25: 229-233.

Gupta MP 1995. 270 Plantas medicinales iberoamericanas. Santafé de Bogotá: Presencia.

Jácome RLRP, Lopes DES, Recio RA, Macedo JF, Oliveira AB 2004. Caracterização farmacognóstica de Polygonum hydropiperoides Michaux e P. spectabile (Mart.) (Polygonaceae). Rev Bras Farmacogn 14: 21-27.

Johansen DA 1940. Plant microtechnique. New York: McGraw Hill Book.

Lageron M 1949. Précis de microscopie. Paris: Masson et Cie.

Leitão F, Fonseca-Kruel VS, Silva IM, Reinert F 2009. Urban ethnobotany in Petrópolis and Nova Friburgo (Rio de
Janeiro, Brazil). Rev Bras Farmacogn 19: 333-342.

Lersten NR, Curtis JD 1992. Foliar anatomy of Polygonum (Polygonaceae): survey of epidermal and selected internal structures. Plant Syst Evol 182: 71-106.

Macedo JF 1993. Informações preliminares sobre a distribuição do gênero Polygonum L. (Polygonaceae) no estado de Minas Gerais. Daphne 3: 39-44.

Mariath IR, Falcão HS, Barbosa-Filho JM, Sousa LCF, Tomaz ACA, Batista LM, Diniz MFFM, Athayde-Filho PF, Tavares JF, Silva MS, Cunha EVL 2009. Plants of the American continent with antimalarial activity. Rev Bras Farmacogn 19: 158-192.

Martins ER, Castro DM, Castellani DC, Dias JE 1995. Plantas medicinais. Viçosa: Imprensa Universitária.

Melo E 2000. Polygonaceae da cadeia do espinhaço, Brasil. Acta Bot Bras 14: 273-300.

Metcalfe CR, Chalk KL 1950. Anatomy of the dicotyledons: leaves, stem, and wood in relation to taxanomy, with notes on economic uses. Oxford: Clarendon Press, v.1.

Mitchell RS 1971. Comparative leaf struture of aquatic Polygonum species. Am J Bot 58: 342-60.

Moore EP, Ashford AE, Peterson RL 1991. Reserve substances in Paxillus involutus sclerotia. Determination by histochemistry and X-ray microanalysis. Protoplasma 163: 67-81.

Oliveira CF, Diel EE, Henriques AT, Schapoval EES, Zettler C 1991. Estudo farmacológico do extrato total de Polygonum hydropiperoides Michaux. Caderno Farm 7 (Supl.): 30-32.

Scavone O, Graeiro A 1970. Contribuição ao estudo anatômico e fitoquímico do Polygonum persicaria L. var. biforme (Wahlenberg) Fries, Polygonaceae. Rev Farm Bioquim 8: 69-89.

Silva-Brambilla MG, Moscheta IS 2001. Anatomia foliar de Polygonaceae (Angiospemae) da planície de inundação do alto Paraná. Acta Scientiarum 23: 571-585.

Simões CMO, Mentz LA, Schenkel EP, Irgang BE, Stehmann JR 1986. Plantas da medicina popular no Rio Grande do Sul. Porto Alegre: Editora Universidade Federal Rio Grande Sul.

Yano, HM 1999. Estudo farmacognóstico e farmacológico de Polygonum persicaria L. São Paulo: Dissertação de Mestrado-Universidade de São Paulo. 